\title{
UMA CAMINHADA DE MODESTAS CONTRIBUIÇÕES, A PARTIR DO NOSSO MESTRADO EM EXTENSÃO RURAL NA UFSM
}

\author{
Francisco Roberto Caporal ${ }^{1}$
}

\section{RESUMO}

Este artigo pretende fazer um resgate sobre a trajetória de dois pesquisadores, Francisco Roberto Caporal e José Antônio Costabeber, com ênfase em algumas das nossas contribuições para a Extensão Rural brasileira e para o avanço da Agroecologia no Brasil. Como marco temporal desta trajetória tomamos como referência o período que começa com nossa experiência de formação junto ao então Curso de Mestrado em Extensão Rural, da Universidade Federal de Santa Maria (UFSM). O artigo destaca algumas passagens de nosso trabalho em conjunto com o colega e amigo, já falecido, José Antônio Costabeber, ao longo de vários anos.

Palavras-chaves: agroecologia, ciências agrárias, extensão rural.

\section{A MODEST WALK CONTRIBUTIONS FROM OUR MASTERS IN RURAL EXTENSION IN UFSM}

\begin{abstract}
This article aims to make a rescue on the trajectory of two researchers, Francisco Roberto Caporal and José Antônio Costabeber, with emphasis on some of our contributions to the brazilian Rural Extension and to the advancement of Agroecology in Brazil. As timeframe this path we take as reference the period that begins with our training experience with the then Master in Agricultural Extension from the Federal University of Santa Maria (UFSM). The article highlights some parts of our work together with colleague and friend, the late José Antônio Costabeber, over several years.
\end{abstract}

Keywords: agroecology, agricultural sciences, rural extension.

\section{INTRODUÇÃO}

Este artigo pretende fazer um resgate sobre a trajetória de dois pesquisadores, Francisco Roberto Caporal e José Antônio Costabeber, com ênfase em algumas das nossas contribuições para a Extensão Rural brasileira e para o avanço da Agroecologia no Brasil. Como marco temporal desta trajetória, tomou-se como referência o período que começa com nossa experiência de formação junto ao

\footnotetext{
${ }^{1}$ Engenheiro agrônomo (UFSM). Mestre em Extensão Rural (UFSM). Doutor em Agroecologia (Universidad de Córdoba, Espanha). Professor da Universidade Federal Rural de Pernambuco (UFRPE). E-mail: caporalfr@gmail.com
} 
então curso de Mestrado em Extensão Rural, da Universidade Federal de Santa Maria (UFSM). O artigo destaca algumas passagens de nosso trabalho em conjunto com o colega e amigo, já falecido, José Antônio Costabeber, ao longo de vários anos.

É importante ressaltar que, formados em Agronomia pela UFSM, na década de 1970, ambos fomos trabalhar na ASCAR - Associação Sulina de Crédito e Assistência Rural (EMATER/RS), em diferentes regiões do estado. Não é preciso dizer que ingressamos no trabalho agronômico no auge da Revolução Verde e que a ação de extensão rural naquela época era totalmente difusionista. Naquela época, nas regiões onde fomos trabalhar, predominavam os cultivos de trigo (às vezes, cevada ou aveia) no inverno e soja e/ou milho no verão. Claro que ainda havia uma importante diversificação da produção de alimentos nas pequenas propriedades, que muitas vezes incluía a criação de animais. Nas casas dos "colonos" com quem trabalhávamos, de descendência italiana ou alemã, ainda havia autossuficiência alimentar e uma alimentação rica e diversificada.

Aquela foi a época da ênfase extensionista no crédito rural e também a época do nascimento do PROAGRO (programa de seguro agrícola). Por diferentes razões climáticas, a maioria de nós extensionistas tínhamos intensas atividades na vistoria de lavouras, ora de trigo, ora de soja, para a elaboração de laudos técnicos necessários para que os agricultores recebessem os benefícios do seguro. $\mathrm{Na}$ verdade, trata-se de um seguro mais para os bancos que para os agricultores, pois, se houvesse perda total na lavoura o seguro pagava ao banco o valor do custeio, mas o agricultor não recebia nada. A ASCAR com os recursos recebidos por conta do serviço de realização dos laudos do PROAGRO entrou numa fase de bonança, renovou sua frota de veículos trocando velhos Jeeps e rural Wyllis por flamantes fusquinhas. Isso significava que a grande maioria de nós extensionistas passávamos meses e meses envolvidos com esta tarefa e pouco tempo tínhamos para o trabalho de Ater. Quando tínhamos, dedicávamos grande parte dele para a elaboração de projetos de crédito ou executando alguns programas demandados pela Empresa Brasileira de Assistência Técnica e Extensão Rural (EMBRATER), financiados pelo Banco Mundial, que eram executados pela ASCAR, que iam da difusão de biodigestores ao programa de introdução de cavalos Percheron em pequenas propriedades.

Como extensionista de campo, por onde começamos, nossa missão era convencer os agricultores a "modernizarem" suas atividades, para superarem as formas "atrasadas" de cultivar e criar animais. Costabeber e eu éramos reconhecidos como extensionistas "competentes", pois alcançávamos as metas planejadas, além de sermos muito disciplinados, coisa que era um valor e uma exigência na extensão rural da época.

Assim, fomos surpreendidos quando, no início dos anos 1980, começaram a aparecer as críticas à extensão rural, em especial por parte de setores mais progressistas da Igreja Católica, primeiro, e logo em seguida por alguns setores da academia. Para nós, aquelas críticas eram absurdas, pois tínhamos convicção de que estávamos ajudando os agricultores. Afinal, éramos nós quem estávamos fazendo os projetos de crédito rural, ensinando os agricultores sobre o uso adequado dos fertilizantes químicos e dos agrotóxicos e difundindo as sementes de milho híbrido, que naquela época eram uma novidade.

Recordo que quando cheguei à Espumoso, primeiro município em que fui trabalhar, escrevi uma apostila que foi distribuída para os agricultores, cujo título era: "Soja: o ouro vegetal". Assim funcionava nossa cabeça de agrônomo-extensionista.

Tudo isso era objeto de crítica e foi na conjuntura daquele momento histórico que acabamos caindo no curso de Mestrado em Extensão Rural, da UFSM 
e, para nossa surpresa, o Costa primeiro e eu logo depois, encontramos o curso em um momento efervescente do seu "repensar" ou pós-repensar. O colega Costabeber fez seu mestrado de 1986 a 1989, sob orientação do professor Gustavo Quesada, sendo que o título de sua dissertação foi: Eficiência energética e processos de produção em pequenas propriedades rurais. Agudo, RS (COSTABEBER, 1989). Sem dúvidas, a dissertação abordou um tema pioneiro nas ciências agrárias do Brasil e da UFSM, pois tratava sobre os balanços energéticos de alguns cultivos presentes no município de Agudo. Cabe lembrar que, à época, as principais referências teóricas sobre este tema vinham de estudos realizados nos Estados Unidos da América.

Eu cheguei depois. Fiz meu mestrado de 1988 a 1991 e minha dissertação recebeu o Prêmio de Menção Honrosa no Congresso da SOBER de 1991, lembrando que, naquela época, outras dissertações do então Curso de Mestrado em Extensão Rural da UFSM também foram premiadas. O tema da dissertação tratou exatamente de fazer uma análise crítica sobre a inércia da extensão rural (no caso da ASCAR/EMATER-RS), que apesar de todos os debates ocorridos a partir de meados dos anos 1980, do chamado "repensar da extensão rural brasileira", não apresentava ou apresentava tímidas mudanças na prática dos extensionistas. O título de minha dissertação, sob orientação do professor José Renato Duarte Fialho, foi: A Extensão Rural e os limites à prática dos extensionistas do serviço público (CAPORAL, 1991).

Cabe destacar que, no período em que fizemos nossos cursos de mestrado, a extensão convencional estava sendo colocada em xeque e o pensamento crítico dava lugar a um debate profundo sobre as transformações necessárias, tanto no ensino como na prática da extensão rural. A maioria de nós estudantes do mestrado, pouco havíamos lido sobre as críticas de Paulo Freire ao agrônomo convencional, o que era constantemente mencionado por nossos professores. Por outro lado, tratar sobre a noção de campesinato nas disciplinas do mestrado foi uma novidade para a maioria.

Eu cheguei ao Mestrado com uma certa bagagem de reflexão crítica, adquirida devido à minha atuação no movimento em defesa da Agricultura Alternativa e pela participação em diversas atividades da Pastoral da Terra, em defesa da Reforma Agrária. Por outro lado, havia participado ativamente na luta pelo Receituário Agronômico e contra os pesticidas organoclorados. Também desenvolvi certo senso crítico na participação como presidente da Associação dos Engenheiros Agrônomos de Cruz Alta e depois de Santa Maria (SASM), um ambiente ainda bastante reacionário naquela época. Mas fizemos trabalhos interessantes. Poucos sabem, por exemplo, que foi em Santa Maria que nasceu a primeira Lei de Agrotóxicos do Brasil, aprovada pela Câmara de Vereadores, fruto da luta da SASM. É importante chamar a atenção para o fato de que, enquanto me preparava para o mestrado, também tive a oportunidade de participar ativamente de eventos e debates do chamado "Repensar da Extensão Rural".

Observe-se que, mesmo com certas reflexões e ativismos, era uma participação pouco politizada, de certa forma com uma ingenuidade típica dos extensionistas. Sair do curso de Agronomia diretamente para as hostes da extensão rural convencional, com direito a um curso obrigatório de Pré-Serviço oferecido pela ASCAR, que durava dois a três meses e onde os técnicos eram imersos no mais puro adestramento Rogeriano, cria uma certa carapaça que nos faz resistentes a mudanças. Nesse treinamento, aprendia-se desde "bons costumes" e "boas maneiras" de como um extensionista deveria se comportar, até como utilizar as "metodologias de extensão"; e claro, passando pelos ensinamentos de como fazer projetos de crédito, além de reforço nas questões técnicas. 
Para ilustrar um pouco a trajetória extensionista, relembramos, no quadro abaixo, uma historinha que o Costabeber não se cansava de contar.

A historinha é mais ou menos assim:

- No primeiro dia de aula da turma do Costabeber, o professor -

acho que era o Quesada, fez aquela tradicional roda de autoapresentações. Havia na turma um colega chamado Doremi, que me parece era baiano.

Cada recém ingressado no Mestrado falou de sua história, trajetória profissional, etc..

Quando chegou a vez do Costabeber, ele contou entusiasmado:

"Sou agrônomo, trabalho na ASCAR/EMATER. Estava trabalhando no município de Três Passos, como extensionista. Lá eu trabalhei muito ensinando os agricultores a usarem corretamente os fertilizantes, a fazer o uso adequado dos defensivos agrícolas (era assim que chamávamos). Também consegui introduzir o milho híbrido na maioria das propriedades assistidas. E por aí foi contando a sua aventura extensionista...

Quando o Costa terminou, o colega Doremi olhou para ele e falou: "Costabeibe (sic), tu fizeste um estrago!!!"

Todos caíram em gargalhadas!

Mais tarde, Costa contava esta história repetidas vezes e me permitia utilizá-la em minhas palestras, para ilustrar como era possível um agrônomo tradicional se transformar num Agroecólogo.

\section{NOSSO REENCONTRO, APÓS O MESTRADO}

Costabeber saiu do mestrado dois anos antes que eu, mas coincidimos um certo período durante o curso. Entretanto, nossa relação se estreitou em alguns momentos muito especiais. Primeiro, nos chamados "seminários etílicos" promovidos pelo professor Quesada e, logo, quando trabalhamos na coordenação da campanha do professor Quesada para reitor. O slogan da campanha era: "Universidade democrática se constrói pela base". Perdemos a eleição, mas fizemos muitos amigos.

Costa e eu nos reencontramos no escritório Regional da ASCAREMATER/RS de Santa Maria, quando conclui o mestrado. À época, havia sido extinta a EMBRATER (1990) e a extensão rural pública no Brasil estava sob coordenação da EMBRAPA. Nós, recém-saídos do mestrado, só pensávamos na possibilidade de fazer o doutorado. Neste ínterim, por coincidência, chegou ao escritório regional da EMATER uma circular da EMBRAPA, me parece que era 1991, oferecendo uma vaga para bolsa de doutorado em Extensão Rural. Embora sabendo que poderíamos concorrer um contra o outro, ambos resolvemos fazer nossos projetos para submeter à EMBRAPA. Foi nesta época que tivemos acesso a um livro que trazia um tema novo e que nos interessou. Tratava-se do livro de Miguel Altieri, intitulado Agroecologia: as bases científicas para a agricultura alternativa.

A partir daí, enquanto elaborávamos os projetos, passamos a procurar onde haviam cursos de doutorado em Extensão Rural. Encontramos dois que nos interessaram, um deles na Universityof Reading, na Inglaterra; e outro na Universidad de Córdoba, na Espanha. O programa de Córdoba nos pareceu mais interessante e começamos as tratativas, com o apoio do professor Fialho, que 
estava fazendo o doutorado lá e que foi quem buscou as cartas de aceite dos professores e nos recebeu quando chegamos.

Quando já tínhamos o aceite da universidade de Córdoba e os projetos prontos, a EMBRAPA deixou a coordenação da Extensão Rural e lá se foi nossa esperança de obter aquela bolsa. Fomos então à Porto Alegre, para falar com o então presidente da EMATER. Contamos nossa história e nossa decepção, e ele, para nossa alegria, garantiu que poderíamos ir para o doutorado e que a EMATERRS garantiria nosso salário e uma bolsa. Voltamos para Santa Maria refletindo sobre o assunto. Era muita sorte! Na sequência, iniciamos um cursinho de espanhol, onde aprendemos que pimentão era "morrones" e moranguinho era "frutilla". Quando chegamos à Espanha, descobrimos que lá eram chamados de "pimientos" e "fresas", respectivamente. Nosso pobre espanhol!

Neste momento, foi quando descobrimos que o CNPq havia aberto edital para Bolsas de Doutorado no Exterior. Decidimos, ambos, enviar nossos projetos para o CNPq e, para surpresa geral, nossos pedidos de bolsa foram aprovados. Creio que foi absoluta obra do acaso, pois ambos atuávamos na mesma instituição, no mesmo escritório e pedimos bolsa para o mesmo curso, na mesma universidade. Coincidência!

Antes de sairmos para o doutorado escrevemos nosso primeiro artigo em conjunto. $O$ título é: Por uma nova extensão rural: fugindo da obsolescência, que foi publicado na Revista da ABRA (CAPORAL; COSTABEBER, 1994). Nele fazemos uma crítica ao modelo convencional de extensão rural e propúnhamos uma extensão alternativa, a partir da ideia de que o modelo convencional já era obsoleto diante dos novos desafios para o desenvolvimento rural e agrícola. Também fazíamos um alerta sobre os impactos socioambientais resultantes do modelo da Revolução Verde, que já eram bastante evidentes, e afirmávamos:

A extensão rural, que sempre optou pelo trabalho junto aos segmentos mais aptos a adotar as tecnologias preconizadas, terá que revisar não só o seu entendimento quanto ao tipo e o papel da tecnologia agropecuária, como, sobretudo, mudar radicalmente sua forma de atuação, para que possa responder adequadamente às exigências impostas pela realidade destas frações de famílias rurais subordinadas. Deve ficar claro, desde já, que apenas com o apoio do serviço de extensão rural e assistência técnica do Estado, não se estará assegurando que estes grupos sociais possam superar as dificuldades hoje vividas. Outras políticas públicas específicas deverão ser buscadas e implementadas com urgência, sabendo-se que este é o público preferencial do Estado e para ele deve ser dada prioridade. (CAPORAL; COSTABEBER, 1994, p. 80). (Observe-se que Costa Beber ainda se escrevia separado, pois foi só quando buscou a cidadania italiana que ele recuperou seu sobrenome de origem).

Nossas afirmações, naquele momento, apontavam que:

Duas referências básicas precisam ser tomadas para se propor uma nova Extensão Rural. A primeira diz respeito à crise do modelo de desenvolvimento imposto ao setor rural, cujo desempenho prático mostrou-se frágil diante da realidade, excludente e concentrador de renda e da terra, além de ter sido responsável por uma enorme degradação ambiental. A segunda referência é quanto a própria extensão rural. 
Adaptada que foi ao modelo, a extensão tradicional tornou-se insuficiente diante do quadro econômico-social dele consequente (Idem, p. 83).

Fruto das nossas reflexões e estudos durante o mestrado (no meu caso, também houve influência de minha participação, desde meados dos anos 80 , em ambientes que discutiam o enfoque da Teologia da Libertação), escrevemos naquele texto:

O extensionista deverá passar a entender o "público" como sujeito da história, respeitando e potencializando sua cultura e seus conhecimentos, favorecendo a ação participativa do grupo familiar e da "comunidade", em detrimento ao paternalismo e das soluções prontas. Ao contrário do modelo "problemsolving", característico dos planos e projetos extensionistas, a nova extensão precisará fortalecer estratégias de valorização e uso adequado dos recursos naturais disponíveis e do potencial humano envolvido, de maneira a favorecer soluções endógenas mais adequadas, de menor custo e sustentáveis sob o ponto de vista econômico e ambiental. A herança deixada, de que a Extensão Rural sempre tem uma "solução" pontual para cada "problema" identificado, tem gerado nos extensionistas uma sensação de impotência no momento em que se deparam com situações-problemas cujas soluções escapam de seus referenciais tecnológicos. Metodologias capazes de assegurar a participação e a ação organizada das famílias rurais, que permitam melhor compreensão das causas dos problemas, o entendimento das consequências destas no processo de desenvolvimento, bem como a possibilidade dialética de partir do concreto para o abstrato, voltando à prática e à reflexão, deverão ser os instrumentos que darão o formato para a atuação extensionista (Idem, p. 86-87).

Nas conclusões daquele texto seminal, de autoria conjunta com Costabeber, nós afirmávamos:

A difusão dos pacotes tecnológicos engendrados nos países industrializados não mostrou, até agora, ter sido a melhor estratégia para tirar a agricultura brasileira do subdesenvolvimento. A atual dependência do setor agrícola por máquinas, equipamentos e insumos, intensivos em capital e energia, aliada a uma maior subordinação aos grandes grupos industriais - fornecedores de insumos e compradores/processadores da produção -, se faz sentir não somente naqueles setores já "modernizados", mas também nas unidades familiares de produção. Continuar a difusão deste modelo, que privilegia o uso de recursos não-renováveis, especialmente o petróleo, e que desemprega a crescente força de trabalho do meio rural, é de fato pouco promissor (idem, $p$. 87). extensionistas,

E alertávamos, também, para a urgência de mudanças na práxis dos

Nesse contexto, a resolução dos problemas mais prementes do público assistido pela extensão rural não passa somente por um "bom difusor", como se apregoava no passado, mas 
pressupõe ações mais democráticas, dialógicas e participativas, capazes de tornar claro como e em que momento a família rural poderá auferir ganhos econômicos e sociais, fruto das inovações e da reorganização do processo produtivo (idem, p. 88).

Revendo tudo isso, 20 anos depois, fica difícil entender porque a maioria do serviço público de extensão rural brasileiro ainda não mudou completamente e, em sua esmagadora maioria, segue dando as costas aos mais pobres do campo e para a problemática social e ambiental, que só se agravaram neste período.

\section{NOSSA TRAJETÓRIA NO DOUTORADO}

Chegamos em Córdoba no final de 1993 e alugamos juntos um apartamento. Nossas famílias foram no início de 1994. Nas "vacaciones" de final do ano de 1993, pegamos um trem para Barcelona, onde um primo meu era treinador de um time de futebol de salão. Ficamos hospedados na casa dele e, como não tinha churrasqueira, fizemos churrasco na lareira da sala. $O$ ataque dos gaúchos!

Nossas atividades no curso de doutorado iniciaram em 1994. Nosso orientador foi, no início, o professor Fernando Sánchez de Puerta (já falecido), que era o especialista em Extensão Rural. Descobrimos, então, que o que eles chamavam de curso de Extensão Rural era, de fato, uma disciplina - que lá chamam curso - e que o doutorado era em Agroecologia, Campesinado e Historia, no Instituto de Sociología e Estudios Campesinos da Universidad de Córdoba, sob coordenação do professor Eduardo Sevilla Guzmán, que acabou sendo o meu orientador.

As disciplinas do doutorado eram distribuídas nos dois primeiros anos e além delas tínhamos um grande número de seminários com figuras importantes da área. Ademais, já funcionava o Máster em Agroecologia e, a convite do professor Eduardo Sevilla Guzmán, nós fazíamos as disciplinas do Máster, na Universidad Internacional de Andalucía, sede de La Rábida, na cidade de Huelva, que ocorria todos os anos. Fizemos o Máster inteiro em 1994 e assistimos várias disciplinas nos anos seguintes. Foi lá que conhecemos os professores Gliessman, Altieri, Clara, Leff, Garrido Peña, Martínez Alier, Naredo, Toledo, Peter Rosset, Xavier Simón, Manolo e tantos outros expoentes da Agroecologia.

Foi em função do Máster que Costabeber e eu escrevemos nosso segundo texto em conjunto. Desafiados pelo professor Eduardo Sevilla Guzmán para fazermos uma apresentação sobre a Extensão Rural do Rio Grande do Sul, escrevemos um texto intitulado Extensión Rural: del difusionismo hacia la agroecología, no qual se criticava o enfoque convencional da extensão gaúcha, mas ao mesmo tempo destacava-se as inúmeras práticas conservacionistas e/ou alternativas que já vinham sendo difundidas por muitos profissionais da EMATERRS. O texto propunha uma reflexão sobre as possibilidades de uma transição a enfoques ambientalmente mais sustentáveis, na prática da extensão rural, que tomaria como ponto de partida a experiência conservacionista já presente no extensionismo. Neste texto, pela primeira vez fazíamos uma aproximação à noção de uma extensão agroecológica, que eu desenvolveria, posteriormente, na minha tese.

Seguindo no mesmo caminho e instigado pela minha trajetória extensionista, escrevi um texto que foi apresentado no Seminário "Passado, Presente e Futuro da Formação, Extensão e Investigação Agrária em Iberoamérica" (1996), realizado na Universidade de Trás-Os-Montes e Alto Douro, em Vila Real Portugal. $O$ título, que refletia a falta de experiência neste sentido, é super longo: La 
Extensión Rural en Brasil y Rio Grande do Sul: una aproximación históricocrítica a los orígenes e influencias teóricas y algunas reflexiones sobre las dificultades conceptuales, controversias y crisis institucional de los años 90 . Neste artigo, muito baseado na minha dissertação de mestrado, aprofundava-se um pouco mais sobre as críticas aos serviços públicos de extensão, tratando, ainda, sobre a crise surgida com o desaparecimento da Empresa Brasileira de Assistência Técnica e Extensão Rural (EMBRATER) e as possibilidades de mudanças que poderiam advir dela.

Concluímos o doutorado em 1998. O Costa estudou as motivações de agricultores que decidiram ingressar na agricultura ecológica no Rio Grande do Sul. Sua tese foi intitulada: Acción colectiva y processos de transición agroecológica en Rio Grande do Sul, Brasil (COSTABEBER, 1998).

Eu segui com o tema da Extensão, agora na perspectiva da Agroecologia, tanto que no capítulo VIII de minha tese, dediquei-me a cunhar um conceito e uma proposta pioneira sobre o que seria uma Extensão Rural Agroecológica. Minha tese teve como título: La extensión agraria del sector público ante los desafios del desarrollo sostenible: el caso de Rio Grande do Sul, Brasil (CAPORAL, 1998).

Cheguei de regresso ao Brasil no fim de 1998 e retomei minhas atividades no Escritório Regional de Santa Maria reassumindo minhas funções de Assistente Técnico Regional. No mesmo escritório também trabalhava Costabeber como Supervisor. Olívio Dutra havia ganho as eleições para governador do RS e a EMATER/RS tinha nova Diretoria, mas faltava ser indicado o Diretor Técnico, que é escolhido por eleições. Eu estava em Santa Maria quando recebi um telefonema de uma pessoa que me perguntou se eu não gostaria de concorrer às eleições para Diretor Técnico. Pedi um tempo para pensar e, enfim, aceitei, acreditando que seria uma boa oportunidade para colocar em prática muitas das coisas que havia estudado. Ganhei as eleições e tomei posse no início de 1999.

Ao começar minhas atividades como Diretor Técnico, a primeira providência foi me cercar de colegas que sabíamos que eram mais progressistas, que viam a necessidade de mudanças e que poderiam colaborar em estratégias e práticas novas dentro da EMATER-RS. A partir disso convidei Costabeber para a Assessoria Técnica. Formamos um grupo formidável de profissionais que, infelizmente, pelo espaço aqui disponível, não poderei citar o nome de todos, mas vale destacar que atribuo a este grupo todos os avanços que foram possíveis obter até 2002.

Com Costabeber trabalhando diretamente comigo, tivemos a oportunidade de realizar uma grande viagem intelectual, além de colocarmos em prática muitas iniciativas que julgo terem sido importantes para a extensão rural gaúcha. Em primeiro lugar, cabe destacar que tudo era pensado e construído com o grupo e depois era colocado em prática a partir de equipes formadas de acordo com suas habilidades e possibilidades. Entre as inciativas adotadas pela EMATER-RS, cabe destacar, aqui, três delas que refuto como fundamentais para os avanços do enfoque agroecológico e da proposta de Extensão Rural Agroecológica, que se tentava construir. Em primeiro lugar, destacaria o grande programa de capacitação dos extensionistas. Iniciamos com palestras e contribuições de intelectuais de diferentes universidades e outras instituições, que foram chamados para formar quadros do escritório central e dos escritórios regionais, a fim de criarmos várias "equipes de formadores". O segundo passo foi a elaboração de um programa comum e a elaboração de materiais educativos e seleção de textos básicos. Vários colegas da equipe contribuíram nestas tarefas. A partir deste momento se iniciou a interiorização do processo de capacitação em todas as regiões administrativas da EMATER-RS, num processo que alcançou a todos os extensionistas de todas as áreas. Cabe lembrar que havia uma parcela importante dos extensionistas que eram 
reacionários à proposta de capacitação, até porque ela iniciava por desconstruir a extensão rural convencional e detalhar os problemas e impactos causados pelo modelo da Revolução Verde a que tínhamos servido como extensionistas. A título de anedota, lembro que em um dos eventos, realizado em Santa Maria, um dos colegas que não estava muito à vontade com a capacitação, chamou o evento de "Doma Racional" e escreveu uma poesia com este título, que iniciava assim: "Certa vez num rodeio/ reuniram os mais sestrosos índios/ de todos com fama estadual/ e o capataz Caporal/ comentou em poucos versos/ dos métodos diversos/ da tal doma racional."

Cabe destacar, por fim, que o programa de capacitação contou com cursos de curta duração, a maioria deles com 80 horas, mas também com cursos em nível de especialização.

Costabeber e eu fomos a um grande número destes eventos e viajávamos muitas vezes juntos, que era a oportunidade para a criação intelectual a que me referirei em seguida. Mas antes cabe lembrar as outras duas iniciativas que ainda faltam mencionar. Numa destas viagens, refletindo sobre o que vínhamos fazendo, julgamos que uma coisa que seria importante era disponibilizar material para leitura, que complementasse de forma periódica a capacitação dos extensionistas. Nasceu daí a ideia de criarmos a Revista Agroecologia e Desenvolvimento Rural Sustentável. Costabeber assumiu a coordenação e a Revista foi e é um sucesso, embora tenha sido interrompida sua edição por um período.

Noutro momento de reflexão, chagamos à conclusão que era preciso massificar os debates e criar uma estratégia para que pudéssemos colocar os extensionistas e agricultores em contato com especialistas em Agroecologia de diferentes lugares do mundo. Nasceu assim o Seminário Estadual e Internacional de Agroecologia, que começou com um púbico em torno de 500 participantes e chegou a contar com mais de 3.000. Fruto destes seminários se criou a Associação Brasileira de Agroecologia. Trouxemos à Porto Alegre, entre 1999 a 2002, mais de uma centena dos mais destacados profissionais do campo da Agroecologia. Costabeber coordenou todos estes seminários, sendo que no ano de 2001, como ilustra a foto abaixo, contamos com o mais expressivo números de expoentes da Agroecologia. 


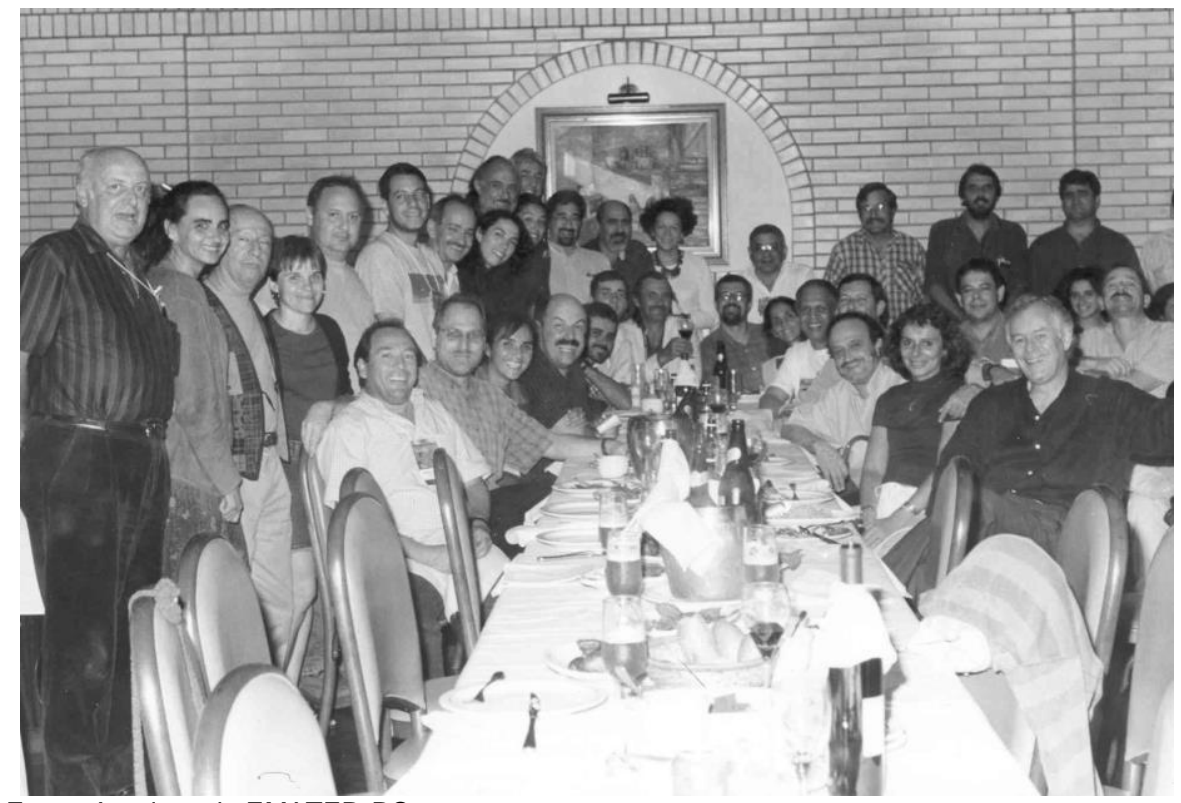

Fonte: Arquivos da EMATER-RS.

Sem dúvidas, os seminários deram uma enorme contribuição para os avanços posteriores da Agroecologia no Rio Grande do Sul e no Brasil, inclusive dentro da EMBRAPA, pois foi nos seminários que se iniciaram os primeiros Encontros de Pesquisadores do campo agroecológico, alguns deles presentes na foto acima.

É fundamental mencionar que todas as iniciativas contaram com a participação e indispensável apoio do Presidente, do Chefe de Gabinete, do Diretor Administrativo e de um grupo excelente de assessores da EMATER-RS, além do núcleo duro de técnicos que trabalhavam conosco.

\section{NOSSA TRAJETÓRIA INTELECTUAL, DE 1999 A 2002}

Paralelo a nossas atividades na Diretoria Técnica e na Assessoria, Costabeber e eu decidimos que deveríamos avançar na produção intelectual, aproveitando que ainda estávamos quentinhos do doutorado. A maioria dos textos que escrevemos em conjunto, neste período, foram pensados durante nossas viagens de trabalho. Nossa ideia era que escrevendo e publicando, poderíamos colocar mais acessível um tema que muitas vezes ainda não estava muito presente na bibliografia corrente e que com isso também estimularíamos a que outros colegas também escrevessem e lessem mais.

Nosso primeiro artigo, neste período, foi escrito em 1999 e publicado na revista da EMATER-RS com o título Agroecologia e Desenvolvimento Rural Sustentável: Perspectivas para uma nova Extensão Rural (CAPORAL; COSTABEBER, 2000). O mesmo artigo, revisado e ampliado foi publicado em Etges (2001) e, também, foi impresso pela EMATER-RS e distribuído a todos os escritórios. Como a ideia era difundir o tema, o texto abundava em conceitos, iniciando pelos enfoques de sustentabilidade e as correntes ecotecnocrática e ecossocial do desenvolvimento sustentável. Também tratava sobre conceitos e 
princípios da Agroecologia, a noção de transição agroecológica e a proposta da adoção da Agroecologia como paradigma diretivo para a ação extensionista.

Em 2002, publicamos outro artigo, na mesma revista, intitulado Agroecologia: enfoque científico e estratégico (CAPORAL; COSTABEBER, 2002a). Nele dizíamos: "Em essência, o enfoque agroecológico corresponde à aplicação de conceitos e princípios da Ecologia, da Agronomia, da Sociologia, da Antropologia, da ciência da Comunicação, da Economia Ecológica e de tantas outras áreas do conhecimento, no redesenho e no manejo de agroecossistemas que queremos que sejam mais sustentáveis através do tempo." (p. 14) Este pequeno artigo é um resumo de um texto maior de 48 páginas, que havia sido publicado pela EMATER-RS, no mesmo ano, destinado à capacitação dos extensionistas, com o título: Agroecologia: enfoque científico e estratégico para apoiar o desenvolvimento rural sustentável (CAPORAL; COSTABEBER, 2002b).

Ainda em 2002, publicamos outro artigo, intitulado Análise Multidimensional da Sustentabilidade: uma proposta metodológica a partir da Agroecologia (CAPORAL; COSTABEBER, 2002c), que também era um extrato do texto anteriormente mencionado. Nele se defendia que a Agroecologia se apresentava como um promissor campo do conhecimento, uma ciência para orientar processos de transição a estilos de agricultura e desenvolvimento rural sustentáveis. Neste texto, definimos a expressão "agricultura de base ecológica" para diferenciar as agriculturas que adotam os princípios da Agroecologia de outros tipos de agriculturas, tanto convencionais, como os modelos de intensificação verde ou de agriculturas baseadas unicamente na substituição de insumos, por exemplo. Destacamos que uma agricultura com base na Agroecologia deveria levar em conta, pelo menos seis dimensões da sustentabilidade, a saber: ecológica, econômica, social, cultural, política e ética.

No mesmo ano, fizemos uma reflexão sobre os avanços e desafios presentes na EMATER-RS e escrevemos: Construindo uma Nova Extensão Rural no Rio Grande do Sul (CAPORAL; COSTABEBER, 2002d). Trata-se de um artigo que tenta destacar as possibilidades de mudanças na prática dos extensionistas, mesmo em organizações do porte da EMATER-RS. Destaque-se, por sua importância, a formação do que foi chamado Colegiados Funcional e Consultivo, criados em 1999, formados por profissionais da Casa que participavam dos processos de decisão da Diretoria da EMATER-RS e a abertura do Conselho Técnico e Administrativo à participação de várias organizações de representação da agricultura familiar, entre outras ações que vinham ocorrendo. Seguramente, este e outros textos na mesma linha, tiveram influência nas orientações adotadas mais tarde, durante a construção da Política Nacional de ATER (PNATER), de 2003.

Por falar em PNATER, em 2003, fui convidado pelo Ministério do Desenvolvimento Agrário (MDA), através da Secretaria da Agricultura Familiar (SAF), para participar do Grupo de Trabalho que teria como missão conduzir o processo de criação de uma Política Nacional de Assistência Técnica e Extensão Rural voltada para o apoio à Agricultura Familiar. Aceitei o desafio. Em setembro do mesmo ano, em um Seminário Nacional, finalmente seria aprovada a Política, que foi sancionada pelo MDA no início de 2004. Fui então convidado para permanecer em Brasília, no Departamento de Assistência Técnica e Extensão Rural (DATER), onde acabei ficando até 2010. Neste período, contamos com a colaboração voluntária de Costabeber, tanto na elaboração e revisão de textos como em muitas das atividades de capacitação que foram promovidas pelo DATER.

Embora trabalhando eu em Brasília e Costabeber em Santa Maria, continuamos a produzir juntos. Em 2003, publicamos, no número 27 da Revista Ciência e Ambiente, da UFSM, um artigo com o título Segurança Alimentar e 
Agricultura Sustentável: uma perspectiva agroecológica (CAPORAL; COSTABEBER, 2003a). Estávamos em pleno lançamento do Programa Fome Zero e tentávamos demonstrar que o modelo de agricultura convencional, produtora de commodities não daria conta de produzir a alimentação para os 44 milhões de pessoas para quem o Programa se propunha a dar pelo menos duas refeições ao dia. O próprio Programa destacava a necessidade de se aumentar em $23 \%$ a produção de leite, $56 \%$ a de feijão, $70 \%$ a de batata, $16 \%$ a de carne, etc, para que fosse possível atender a demanda que seria criada. A partir daí, propúnhamos que a adoção do enfoque agroecológico seria muito mais propicia ao atendimento da necessária Segurança Alimentar e Nutricional Sustentável, até porque isso exigiria, além da quantidade, uma alimentação de melhor qualidade, sem contaminantes.

Também em 2003, publicamos o artigo Possibilidades e alternativas do desenvolvimento rural sustentável (CAPORAL; COSTABEBER, 2003b), em um livro organizado pelo colega Hugo Vela. Nele fazíamos uma discussão crítica sobre os conceitos de desenvolvimento e desenvolvimento sustentável e propúnhamos como alternativa a adoção do enfoque agroecológico, visando alcançar estilos de agricultura de base ecológica. Ademais, como estratégias para o DRS, se propunha, entre outras coisas: a) opção pela agricultura familiar; b) aposta em nova formas de comercialização; c) ter como referência a dimensão local do desenvolvimento; d) novas forma de planejamento participativo; e) fortalecimento dos circuitos curtos, aproximando os consumidores dos agricultores.

Seguindo na mesma trajetória, em 2004, publicamos o livro Agroecologia e Extensão Rural: contribuições para a promoção do desenvolvimento rural sustentável (CAPORAL e COSTABEBER, 2004a). Trata-se da seleção de vários artigos ainda não publicados ou já publicados anteriormente, que procuram, no seu conjunto, apresentar as possibilidades da articulação entre Extensão Rural e Agroecologia. No Prefácio deste livro, Miguel Altieri escreveria: "O livro (...) nos alerta sobre os desafios que toda a organização de extensão rural vinculada ao setor público deve enfrentar para sair de seu imobilismo e transformar-se em uma instituição dinâmica, impulsionadora de um novo enfoque participativo e agroecológico de desenvolvimento rural.". Foi publicada uma segunda edição deste livro em 2007, e ao todo foram distribuídos, gratuitamente, 2000 exemplares.

Ainda em 2004, publicamos o artigo Análise multifuncional da sustentabilidade: uma proposta metodológica a partir da Agroecologia (CAPORAL; COSTABEBER, 2004b), num livro organizado pelos colegas Froehlich e Diesel. Trata-se de uma revisão ampliada do artigo de 2002, já mencionado.

Continuando nossa contribuição à Extensão Rural brasileira, em 2006, iniciando as primeiras avaliações sobre avanços e limites das organizações públicas de ATER, frente aos desafios apresentados pela Política Nacional de ATER, publicamos, com Ladjane (minha esposa), o artigo intitulado Da extensão rural convencional à extensão rural para o desenvolvimento sustentável: enfrentar desafios para romper a inércia (CAPORAL; RAMOS, 2006). Passados cerca de 3 anos desde a construção e início da implementação da PNATER, observava-se que as organizações públicas de ATER estavam enfrentando sérias dificuldades para implementar as orientações da Política, pois não conseguiam romper com suas trajetórias históricas e seu viés difusionista. Apresentávamos a sugestão de alguns indicadores para medir o sucesso das entidades em relação à PNATER a fazíamos um conjunto de recomendações de mudanças, que iam desde a questão do papel e postura dos técnicos até a problemática das estruturas institucionais.

Em 2006, em conjunto com os companheiros Costabeber e Gervásio Paulus, publicamos outro artigo, intitulado Agroecologia: matriz disciplinar ou novo paradigma para o desenvolvimento rural sustentável (CAPORAL; 
COSTABEBER; PAULUS, 2006). Este artigo despertou grande interesse e foi publicado em vários lugares, entre os quais destacamos o livro Extensión: reflexiones para la intervención em el medio urbano y rural, editado pelos companheiros uruguaios Tommasino e Hegedüs. Nesse texto dedicamos uma atenção à questão da ética como um dos princípios da Agroecologia. Trata-se da "ética ambiental" ou da "ética do cuidado", uma vez que se a Agroecologia se propõe como matriz disciplinar ou uma ciência que quer contribuir com o desenvolvimento mais sustentável, não poderá abrir mão de uma perspectiva de solidariedade intrageracional, quer dizer, para com aqueles que ainda nem existem, as futuras gerações. Avançamos, também, em outro aspecto, ao mostrar que além dos saberes tradicionais, os conhecimentos dos povos do campo, a Agroecologia lança mão de conhecimentos de distintos campos das ciências, na perspectiva de dar conta da abordagem sistêmica e holística a que se propõe.

Entre outros materiais publicados neste ínterim, em 2011, num livro organizado por nosso companheiro mexicano Jaime Morales, publicamos um artigo, escrito em fins de 2009, com o título: La extensión rural con enfoque agroecológico y las políticas públicas hacia a la sustentabilidad rural (CAPORAL; COSTABEBER, 2011). Neste artigo, além de um resgate do cenário atual, tratamos de destacar a importância das políticas públicas para impulsionar o desenvolvimento mais sustentável, como um imperativo da nossa época, sobre alguns aspectos da extensão necessária para isso. E concluímos com um pequeno apanhado do que vinha acontecendo com a extensão rural no Brasil a partir da PNATER de 2003.

Por último, cabe destacar o artigo intitulado 0 conceito de transição agroecológica: contribuições para o redesenho de agroecossistemas em bases sustentáveis. (COSTABEBER; CAPORAL; WIZNIEWSKY, 2013). Foi publicado "IN MEMORIAM", pois nosso amigo Costabeber nos havia deixado, tendo falecido antes de sair a publicação da EMBRAPA. No artigo, tenta-se um aprofundamento sobre o conceito de transição agroecológica e da sua importância para o enfrentamento dos graves problemas antrópicos que vem se acumulando desde o advento da Revolução Verde.

\section{COMO CONCLUSÃO}

Em atenção ao editor deste dossiê sobre os 40 anos do PPGExR, procuramos destacar, neste artigo, um pouquinho da trajetória intelectual e das contribuições que, conjuntamente, Costabeber e eu, algumas vezes com outros parceiros, modestamente, procuramos dar não só para a Extensão Rural, mas também para o fortalecimento da Agroecologia como uma nova e potente ciência para a sustentabilidade. Os textos citados são uma parte de nossa produção conjunta. Não demos ênfase a nossas publicações individuais e também deixamos muitas coisas de fora, pois seria demasiado cansativo para os leitores.

A ideia central foi mostrar que, a partir de nossa formação no então Mestrado de Extensão Rural da Universidade Federal de Santa Maria (UFSM), nossa trajetória de vida e nossa trajetória profissional e intelectual teve um câmbio importante. Saímos da condição de extensionistas convencionais, competentes difusionistas, para uma nova perspectiva, em defesa de uma Extensão Rural democrática, participativa e que pudesse contribuir para os ideais de sustentabilidade de nossa época. Abraçamos a Agroecologia como o enfoque científico capaz de ajudar a superar os grandes problemas socioambientais gerados pelos modelos de desenvolvimento rural e de agricultura convencionais e que 
poderia reorientar 0 extensionismo na perspectiva da sustentabilidade socioambiental.

Neste caminhar, procuramos dar nossa contribuição no campo das instituições de ATER e das políticas públicas e acabamos, ambos, como professores universitários. Nossa trajetória de vida, com seus altos e baixos, foi marcada pelo desejo de buscar uma sociedade mais fraterna, mais humanizada e mais sustentável ambientalmente. Uma parte desta luta nós lutamos juntos, lado a lado. Por isso, por vezes, foi difícil para mim escrever este texto. Se o fiz, foi porque entendi que seria a única pessoa capaz de fazê-lo, por ser partícipe da história. Além disso, fui motivado pelo sentimento de registrar mais uma homenagem ao Costinha, como eu o chamava carinhosamente. Neste sentido, agradeço ao editor do dossiê pelo convite e pela oportunidade de escrever este texto.

Finalizando, gostaríamos de expressar nossos agradecimentos ao então Curso de Mestrado e atual Programa de Pós-graduação em Extensão Rural da UFSM e a todos os professores que compartilharam conosco seus conhecimentos e nos deram ânimo para seguir em frente. Também parabenizamos a todos os alunos e professores que seguraram o curso com a sua alta qualidade, ao longo dos anos. Por isso mesmo, queremos deixar aqui os nossos cumprimentos pelos 40 anos deste Programa de Pós-Graduação, que ao longo de sua história ajudou a transformar tantas mentes e tantos corações. Que dure muito!

\section{REFERÊNCIAS}

CAPORAL, F. R. A extensão rural e os limites à prática dos extensionistas do serviço público. 1991. 221p. Dissertação (Mestrado). Programa de Pós-Graduação em Extensão Rural. Santa Maria: UFSM, 1991.

CAPORAL, F. R. La extensión agraria del sector público ante los desafíos del desarrollo sostenible: el caso de Rio Grande do Sul, Brasil. 1998. 517p. Tese (Doutorado). Programa de Doctorado en Agroecología, Campesinado e Historia, ISEC-ETSIAN, Universidad de Córdoba, España, 1998.

CAPORAL, F. R. La extensión rural en Brasil y Rio Grande do Sul: Una aproximación histórico-crítica a los orígenes e influencias teóricas y algunas reflexiones sobre las dificultades conceptuales, controversias y crisis institucional de losaños 90. (Mimeo), 1996, 32p. Versão preliminar preparada para apresentação no Seminário "Passado, Presente e Futuro da Formação, Extensão e Investigação Agrária em Ibero américa" (13 e 14.02.1996). Universidade de Trás-Os-Montes e Alto Douro, Vila Real - Portugal.

CAPORAL, F. R.; COSTABEBER, J. A. Agroecologia e desenvolvimento rural sustentável: perspectivas para uma nova extensão rural. Agroecologia e Desenvolvimento Rural Sustentável, v. 1, n. 1, jan./mar., p. 16-35, 2000.

CAPORAL, F. R.; COSTABEBER, J. A. Agroecologia e desenvolvimento rural sustentável: perspectivas para uma nova extensão rural. In: ETGES, V. E. Desenvolvimento rural: potencialidades em questão. Santa Cruz do Sul: EDUSC, 2001. p. 19-52.

CAPORAL, F. R.; COSTABEBER, J. A. Agroecologia e extensão rural: contribuições para a promoção do desenvolvimento rural sustentável. Brasília: MDA/SAF/DATER-IICA, 2004a. 
CAPORAL, F. R.; COSTABEBER, J. A. Agroecologia: enfoque científico e estratégico. Agroecologia e Desenvolvimento Rural Sustentável, v. 3, n. 2, abr./jun., p. 13-16, 2002a.

CAPORAL F. R.; COSTABEBER, J. A. Agroecologia: enfoque científico e estratégico para apoiar o desenvolvimento rural sustentável (texto provisório para discussão). Porto Alegre: EMATER/RS-ASCAR, 2002b. (Série Programa de Formação Técnico-Social da EMATER/RS. Sustentabilidade e Cidadania, texto 5).

CAPORAL, F. R.; COSTABEBER, J. A. Análise multidimensional da sustentabilidade: uma proposta metodológica a partir da agroecologia. Agroecologia e Desenvolvimento Rural Sustentável, v. 3, n. 3, jul./set., 2002c.

CAPORAL, F. R.; COSTABEBER, J. A. Análise multidimensional da sustentabilidade; uma proposta metodológica a partir da agroecologia. In: FROEHLICH, J. M.; DIESEL, V. Espaço rural e desenvolvimento regional: estudos a partir da região central do RS. ljuí: Ed. Unijui, 2004b. p. 127-148.

CAPORAL, F. R.; COSTABEBER, J. A. Construindo uma nova extensão rural no Rio Grande do Sul. Agroecologia e Desenvolvimento Rural Sustentável, v. 3, n. 4, out./dez., p.10-15, 2002d.

CAPORAL, F. R.; COSTABEBER, J. A. Extensión rural: del difusionismo hacia la agroecología. (Mimeo), 1995. 65p. Versión preliminar presentada en el Ciclo de Cursos y Seminarios sobre Agroecología y Desarrollo Sostenible en América Latina y Europa (4ํ Módulo: "Transición Agroecológica" - 26 a 30 de junio de 1995). Universidad Internacional de Andalucía - Sede Iberoamericana de La Rábida Huelva (España).

CAPORAL, F. R.; COSTABEBER, J. A. La extensión rural con enfoque agroecológico y las políticas públicas hacia la sustentabilidade rural. In: MORALEZ HERNÁNDEZ, J. La agroecología en la construcción de alternativas haciala sustentabilidade rural. México: Siglo XXI Editores/Instituto Tecnológico y de Estudios Superiores de Occidente, 2011. p. 190-215.

CAPORAL, F. R.; COSTABEBER, J. A. Por uma nova extensão rural: fugindo da obsolescencia. Reforma Agrária, v. 24, n. 3, p. 70-90, 1994.

CAPORAL, F. R.; COSTABEBER, J. A. Possibilidades e alternativas do desenvolvimento rural sustentável. In: VELA, $H$. Agricultura familiar e desenvolvimento rural sustentável no Mercosul. Santa Maria: Palloti, 2003b. p. 157-194.

CAPORAL, F. R.; COSTABEBER, J. A. Segurança alimentar e agricultura sustentável: uma perspectiva agroecológica. Ciência \& Ambiente, n. 27, p. 153165, 2003a.

CAPORAL, F. R.; COSTABEBER, J. A.; PAULUS, G. Agroecologia: matriz disciplinar ou novo paradigma para o desenvolvimento rural sustentável. In: TOMMASINO, H.; HEGEDÜS, P. Extensión: reflexiones para la intervenciónenel médio urbano y rural. 
Montevideo: Departamento de Publicaciones de la Facultad de Agronomía de la Universidad de la República, 2006. p. 45-63.

CAPORAL, F. R.; RAMOS, L. F. Da extensão rural convencional à extensão rural para o desenvolvimento sustentável: enfrentar desafios para romper a inércia. In: MONTEIRO, D. M. C.; MONTEIRO, M. A. Desafios na Amazônia: uma nova assistência técnica e extensão. Belém: UFPA/NAEA, 2006. p. 27-50.

COSTABEBER, J. A. Acción colectiva y procesos de transición agroecológica en Rio Grande do Sul, Brasil. 1998. 422p. Tese. (Doutorado) - Programa de Doctorado en Agroecología, Campesinado e Historia, ISECETSIAN, Universidad de Córdoba, España.

COSTABEBER, J. A. Eficiência energética e processos de produção em pequenas propriedades rurais. Agudo, RS. Santa Maria: UFSM, 1989. p. 295. Dissertação de Mestrado em Extensão Rural.

COSTABEBER, J. A.; CAPORAL, F. R.; WIZNIEWSKY, J. G. O conceito de transição agroecológica: contribuições para o redesenho de agroecossistemas em bases sustentáveis. In: GOMES, J. C. C.; ASSIS, W. S. Agroecologia: princípios e reflexões conceituais. Brasília: EMBRAPA, 2013. p. 145-180. 